\title{
Beneficial Reuse of Corrugated Board in Slurry Applications
}

\author{
James L. Hanson, M. ASCE, Nazli Yesiller, A.M. ASCE, Jagjit Singh , Greg M. \\ Stone, S.M. ASCE, and Adam Stephens
}

\begin{abstract}
Use of virgin and post-consumer corrugated board as a replacement for bentonite in slurry mixes was investigated. The effectiveness of the slurry mixes was assessed using typical tests including Marsh funnel viscosity, density, and filtrate loss. Filter cake permeability uas also determined. Corrugated board was fiberized for the test program. Test results indicated that corrugated board could be used to replace 9 to $27 \%$ ( 0.5 to $1.5 \%$ corrugate content) of bentonite in slurry mixes with a total solids content of $5.5 \%$. Slurry applications provide a new and viable beneficial reuse alternative for paper/paperboard products, which constitute the largest weight and volume fraction of municipal solid waste generated and disposed of in the U.S.
\end{abstract}

\section{INTRODUCTION}

Bentonite slurries are used in construction of vertical cutoff walls for geotechnical and geoenvironmental applications. The construction of cutoff walls typically is a step-by-step process, where a trench is excavated, filled first with slurry, and then backfill. The slurry covers the inside walls of the trench forming a low permeability filter cake layer. The slurry also provides hydrostatic pressure to keep the trench open prior to placement of the backfill. Typical slurries consist of 4 to $7 \%$ bentonite and 93 to $96 \%$ water by weight (Boyes 1975). Paper and paperboard constitute the highest fraction by both weight and volume of municipal solid waste generated (32.7\% by weight) and disposed of $(22.3 \%$ by weight) in the U.S. The amount of paper and paperboard generated and disposed of was 83 million and 37.8 million tons in 2007, respectively (USE:PA 2009). The use of recovered paper in manufacturing containerboard has remained stable at approximately 16 million tons since 1997 (Paper Industry Association Council 2008). An economical limit for incorporating 
waste papers into containerboard has been reached. Some corrugated board is not suitable for conventional recycling due to presence of contamination. Pizza boxes are a common example, which comprise nearly $1 \%$ of the total annual production of 313 million $\mathrm{m}^{2}$ of corrugated board (Flaherty 2009). Residue on pizza boxes is problematic for recycling as grease prevents absorption of moisture, proper pulping of paper fiber, and quality of binding of fibers in recycled paper (RecycleBank 2009). Innovative recycling options (beyond the packaging industry) need to be investigated to promote beneficial reuse of paper products. This study has been conducted to evaluate reuse of paper and paperboard in civil engineering applications. Results from the portion of the study with use of corrugated board in slurry applications are presented herein.

\section{EXPERIMENTAL TEST PROGRAM}

Tests were conducted to assess the feasibility of using corrugated board in slurry mixtures. Bentonite was replaced by corrugated board at varying ratios. Properties of bentonite-board-water mixes were compared to baseline bentonite-water mixes to evaluate the influence and practical limits of corrugated board addition.

\section{Materials}

A commercially available standard powder bentonite was used in the test program. Baroid AQUAGEL is a finely ground, premium-grade Wyoming sodium bentonite that meets the American Petroleum Institute (API) Specification 13A, section 4 requirement. The bentonite had a liquid limit $=539$, plastic limit $=82$, and specific gravity $=2.65$. Corrugated board was selected as the paper/paperboard product due to the significant quantities available lor reuse. Tests were conducted on non-waxed products. Two types of corrugated board were used in the test program: conventional box material ( $c$-flute corrugated board) and pizza boxes. Identical products for virgin (V) and post-consumer (PC) corrugated board were tested to determine potential effects of use on the properties of corrugated board in slurry applications. The c-flute corrugated board was subjected to standardized laboratory conditioning as prescribed by ISTA (2009) to provide post-consumer status. The post consumer pizza boxes were collected from a garbage bin and contained representative amounts of food product (i.e., grease and food remains) residue. The corrugated board samples were fiberized by mixing with water in a Waring $\mathrm{cb} 15$ stainless steel 4-L capacity blender that contained a specially fabricated blade adhering to the specifications outlined by White and Kendrick (2009).

\section{Corrugated Board Tests}

Tests (summarized in Table 1) were conducted on virgin and post-consumer corrugated board to determine material properties. The corrugated board properties are presented in Table 2. The edge crush and water absorption tests on corrugated board provided indication of the fiberization potential and shredding of the corrugated board for the proposed slurry application. 
Table 1. Corrugated Board Tests

\begin{tabular}{|c|c|c|}
\hline Test Name & $\begin{array}{l}\text { Standard } \\
\text { Designation }\end{array}$ & Description of 'Test \\
\hline $\begin{array}{l}\text { Grammage of paper and } \\
\text { paperboard (weight per } \\
\text { unit area) }\end{array}$ & $\begin{array}{l}\text { TAPPI } \\
\text { T } 4100 \mathrm{om}-() 2\end{array}$ & $\begin{array}{l}\text { Weight per } 92.90 \mathrm{~m}^{2} \text { of all three containerboard } \\
\text { components of a single wall corrugated fiberboard is } \\
\text { determined after conditionıng for } 24 \text { hours at } 21 \pm 1^{\circ} \mathrm{C} \\
\text { lemperature and } 52 \pm 0.5 \% \mathrm{RHI} \text {. }\end{array}$ \\
\hline $\begin{array}{l}\text { Bursting strength of } \\
\text { corrugated and solid } \\
\text { fiberboard }\end{array}$ & $\begin{array}{l}\text { TAPPI } \\
\text { T810 om-06 }\end{array}$ & $\begin{array}{l}\text { Square corrugated fiberboard samples with dimension } \\
31.50 \pm 0.03 \mathrm{~mm} \text { are tested by distending an expansible } \\
\text { diaphragm under a pressure of } 690 \mathrm{kPa} \text { to } 4825 \mathrm{kPa} \text {. }\end{array}$ \\
\hline $\begin{array}{l}\text { Edgewise compressive } \\
\text { strength of corrugated } \\
\text { fiberboard }\end{array}$ & $\begin{array}{l}\text { TAPPI } \\
\text { T839 om-02 }\end{array}$ & $\begin{array}{l}\text { A test specimen with length } 50.8 \pm 0.8 \mathrm{~mm} \text { and height } \\
25.4 \pm 0.4 \mathrm{~mm} \text { is compressed vertically (load parallel to } \\
\text { Mutes) to failure at the rate of } 111 \pm 22 \mathrm{~N} / \mathrm{s} \text {. }\end{array}$ \\
\hline $\begin{array}{l}\text { Water absorptiveness of } \\
\text { corrugated tiberboard } \\
\text { (Cobb test) }\end{array}$ & $\begin{array}{l}\text { TAPPI } \\
1+410 \mathrm{om}-04\end{array}$ & $\begin{array}{l}\text { A sample with a diameter of } 11.28 \pm 0.02 \mathrm{~cm} \text { is exposed } \\
\text { to } 100 \mathrm{~mL} \text { of water }\left(23 \pm 1{ }^{\circ} \mathrm{C}\right) \text { and a head of } 1 \pm 0.1 \mathrm{~cm} \\
\text { for } 120 \text { seconds. }\end{array}$ \\
\hline
\end{tabular}

Table 2. Corrugated Board Properties

\begin{tabular}{|c|c|c|c|c|}
\hline Material & $\begin{array}{c}\text { Weight/Unit Area } \\
\left(\mathbf{g} / \mathbf{m}^{\mathbf{2}}\right)\end{array}$ & $\begin{array}{c}\text { Burst Strength } \\
(\mathbf{k P a})\end{array}$ & $\begin{array}{c}\text { Edge Crush } \\
(\mathbf{N})\end{array}$ & $\begin{array}{c}\text { Cobb Test } \\
\left(\mathbf{g} / \mathbf{m}^{\mathbf{2}}\right)\end{array}$ \\
\hline V c-flute box & 579 & 1350 & 162 & 78.3 \\
\hline PC c-flute box & 588 & 1140 & 146 & 89.0 \\
\hline V pizza box & 447 & 900 & 155 & 94.3 \\
\hline PC pizza box & 493 & 1025 & 165 & 99.0 \\
\hline
\end{tabular}

\section{Slurry Tests}

Slurry mixes were prepared using bentonite and water and also using bentonite, fiberized corrugated board, and water. Visual comparison was made for the solids suspension / sedimentation behavior of the bentonite and fiberized corrugated board by allowing mixtures to settie in hydrometer jars and by centrifugation. Example photographs of the slurries are presented in Fig. 1. The centrifuge was run at 1500 rpm for 1 minute to assess segregation and sedimentation in the mixtures. At high fiber ratios, the homogeneity of the slurries was decreased as flocculation and segregation of the fibers occurred (presence of clear water within the grab samples and at the top of the centrifuge samples). Bentonite dispersed in water and remained in suspension for extended periods of time, whereas the paper fibers alone flocculated in the presence of water and became segregated from the bentonite with time. In addition, high corrugate content mixtures exhibited gas production within 5-6 days of mixing, which remained entrapped within the fiber matrix. Overall, fiber-only and low-bentonite content mixes $(<2.5 \%$ bentonite) were deemed inappropriate to provide effective slurry behavior. Solids remained in suspension for slurry mixtures that contained both tibers and sufficient amounts of bentonite. The specific mixtures tested for slurry behavior were based on these observations.

All mix ratios are provided on weight basis (Table 3 ). Tap water was used for all slurry mixes. The water was conditioned to a pH of $8.5 \pm 0.12$ using small amounts of soda ash before solids were added to the slurry mixtures. Pure bentonite slurries were mixed in a blender on low speed for 2 minutes prior to testing. For slurries containing corrugated board, water and corrugated board were mixed on low speed 
for a 2-minute period to allow corrugate to be pulped into fibers, then mixed again after the addition of bentonite for an additional 2 minutes. The post-consumer corrugated board was more difficult to pulp than the virgin corrugated board. The original pulping period of 2 minutes was increased to 5 minutes for post-consumer corrugated board samples in subsequent tests to investigate the effect of increased pulping duration on the engineering properties of the slurry mixtures.
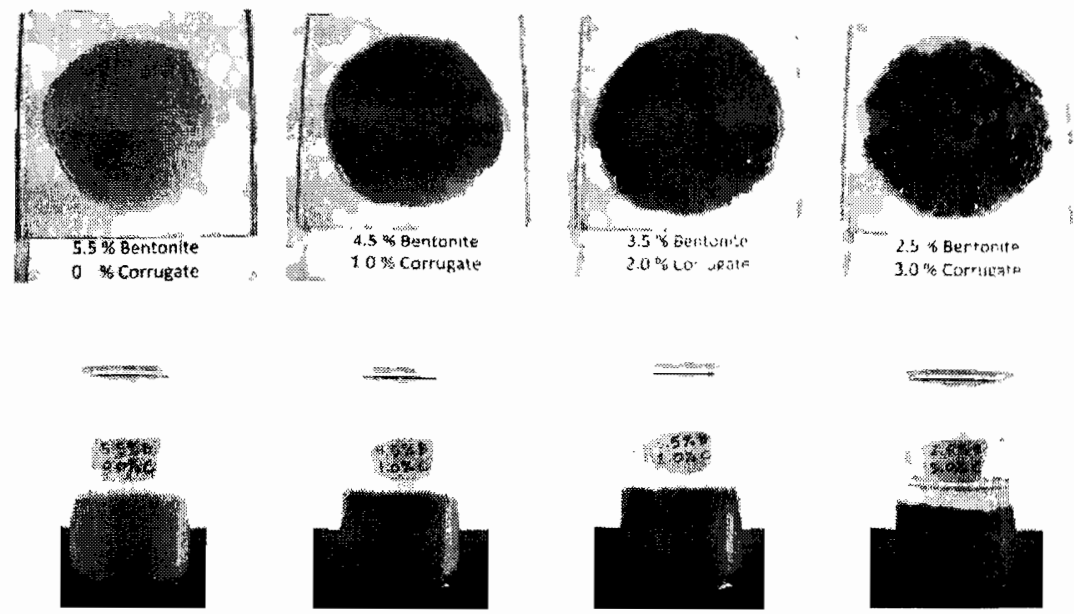

Figure 1. Comparison of Slurry Mixtures (grab and centrifuge samples)

Table 3. Slurry Mix Ratios

\begin{tabular}{|c|c|c|c|c|}
\hline Mix Number & $\begin{array}{l}\text { Corrugate } \\
\text { Type }\end{array}$ & $\begin{array}{c}\text { Bentonite } \\
(\%)\end{array}$ & $\begin{array}{c}\text { Corrugated Board } \\
(\%)\end{array}$ & $\begin{array}{c}\text { Water } \\
(\%)\end{array}$ \\
\hline 350 & None & 5.0 & 0 & 95 \\
\hline$B 55$ & None & 5.5 & 0 & 945 \\
\hline $\mathrm{B} 6.0$ & None & 6.0 & 0 & 94 \\
\hline V0.5 & Virgin & 5.0 & 0.5 & 94.5 \\
\hline V1.0 & Virgin & 4.5 & 1.0 & 94.5 \\
\hline $\mathrm{V} 1.5$ & Virgin & 4.0 & 1.5 & 94.5 \\
\hline $\mathrm{V} 2.0$ & Virgin & 3.5 & 2.0 & 94.5 \\
\hline$V 2.5$ & Virgin & $3 .()$ & 2.5 & 94.5 \\
\hline V3.0 & Virgin & 2.5 & 3.0 & 94.5 \\
\hline$P C 0.5$ & Post-consiumer & 5.0 & 0.5 & 94.5 \\
\hline$P(10)$ & Posi-comsumer & 4.5 & 1.0 & $94 . \overline{5}$ \\
\hline $\mathrm{PC} 1.5$ & Post-consumer & 4.0 & $1 . \overline{5}$ & 94.5 \\
\hline$P C 2.0$ & Post-consumer & 3.5 & 2.0 & 94.5 \\
\hline $\mathrm{PC} 2.5$ & Post-consumer & 3.0 & 2.5 & $94 . \overline{5}$ \\
\hline$P(3.0$ & Post-consumer & 2.5 & 3.0 & 94.5 \\
\hline
\end{tabular}

Typical slurry tests (D)Appolonia 1980, USEPA 1984) were used in the experimental program: Marsh funnel viscosity (ASTM D 6910); mud balance (ASTM 
D 4380); filter press (API Recommended Practice 13B); and filter cake permeability (conducted in conjunction with / immediately following API Recommended Practice 13B). Standardized test methods were generally followed. In order to prevent segregation of paper fibers from the slurries, the mixtures containing fibers were not poured through the attached funnel screen in Marsh funnel testing. The thickness of the filter cake was measured by averaging values determined at three locations on the cake using a pair of digital calipers. Thickness of the filter cake was measured after permeability tests had been conducted to minimize damage and disturbance to the filter cake. Separate tests were conducted to verify that filter cake thickness did not change during the permeability stage of the experiments. The permeability tests were conducted using a pressure differential of $140 \mathrm{kPa}$. The hydraulic gradient varied depending on the thickness of the tilter cake and was on the order of 5,000.

\section{RESULTS AND DISCUSSION}

The results of the slurry tests are provided in Table 4. The Marsh funnel viscosity of the bentonite-water slurry mix was equal to $40.5 \mathrm{~s}$ for the $5.5 \%$ solids content and this mixture was established as the baseline mixture for the tests. The total solids content of the mixes containing both bentonite and corrugated board was set to $5.5 \%$. The viscosity of the mixture with $5 \%$ bentonite was in general similar to the baseline mix, whereas the $6 \%$ bentonite mix had higher viscosity and density and lower filter cake thickness than the baseline mix. For mixes containing bentonite, corrugated board, and water, viscosity, filter loss, filter cake thickness, and filter permeability generally increased with increasing corrugate content. Mud balance density generally decreased with increasing corrugate content.

Acceptable slurry mix properties were established as: Marsh funnel viscosity of approximately $40 \mathrm{~s}$ (up to $50 \mathrm{~s}$ was deemed acceptable for this test program); density of 1010-1040 kg/min; and tiltrate loss of less than $30 \mathrm{ml}$ based on specifications provided in USEPA (1984) and Ryan and Day (2003). The variations of Marsh funnel viscosity, density, filtrate loss, and permeability as a function of corrugate content are presented in Fig. 2. Shaded regions in the plots in Fig. 2 represent areas that are outside acceptable limits for Marsh funnel viscosity, mud balance density, and filtrate loss. In general, mixtures up to approximately $1.5 \%$ corrugate content (baseline, $\mathrm{V}$ mixes up to $1.5 \%, \mathrm{PC}$ mixes up to $1.0 \%$, and $\mathrm{PC}(+)$ mixes up to $2 \%$ corrugate content, Table 4) maintain acceptable engineering properties. The corrugated board can be used to replace 9 to $27 \%(0.5$ to $1.5 \%$ corrugate content in a $5.5 \%$ mixture) of the bentonite used in the slurry mixes. In addition, the PC2.0-P(+) slurry (2\% corrugate) and other $2 \%$ corrugate slurry mixtures were close to the acceptable range and may be used based on specific site and construction conditions. Significant amount of this natural resource (i.e., bentonite) can be saved using the corrugated board, in consideration to large-scale construction projects.

The differences between virgin and post-consumer board were not significant with regard to performance in slurry mixes. The changes in engineering properties of the slurries with added corrugate content were attributed to the fibrous structure of the corrugate. Specifically, a librous matrix developed with sufficient addition of corrugate, which promoted more viscous, less cohesive behavior. This resulted in an 
increase in Marsh funnel viscosity (up to 2.5 corrugate content beyond which Marsh funnel readings could not be obtained due to excessive bridging of the fibers in the testing device); a decrease in mud balance density (due to replacement of bentonite with the lighter fibers); and increase in filtrate loss and permeability (attributed to presence of sufficient tiber content to provide preferential pathways for flow).

Table 4. Slurry Test Results

\begin{tabular}{|c|c|c|c|c|c|c|c|}
\hline $\begin{array}{c}\text { Corrugate } \\
\text { Type }\end{array}$ & Mix & $\begin{array}{c}\text { MFV } \\
\text { (s) }\end{array}$ & $\begin{array}{c}\mathrm{MB} \\
\left(\mathrm{kg} / \mathrm{m}^{3}\right)\end{array}$ & $\begin{array}{c}\text { FL } \\
(\mathrm{mL})\end{array}$ & $\begin{array}{c}\mathrm{CT} \\
(\mathrm{mm})\end{array}$ & $\begin{array}{c}k / t \\
\left(s^{-1}\right) \\
\end{array}$ & $\begin{array}{c}k \\
(\mathrm{~cm} / \mathrm{s})\end{array}$ \\
\hline \multirow{3}{*}{ None } & B5.0 & 38.3 & 1030 & 19 & 2.4 & $4.68 \times 10^{-8}$ & $1.12 \times 10^{-8}$ \\
\hline & B5.5 & 40.5 & 1030 & 16 & 2.7 & $4.89 \times 10^{-8}$ & $1.33 \times 10^{.8}$ \\
\hline & B6.0 & 49.2 & 1035 & 14 & 1.8 & $3.24 \times 10^{-8}$ & $5.93 \times 10^{8}$ \\
\hline \multirow{18}{*}{ C-flute box } & V0.5-C & 42.4 & 1025 & 19 & 3.8 & $4.20 \times 10^{-8}$ & $1.58 \times 10^{-8}$ \\
\hline & $\mathrm{VI} .0-\mathrm{C}$ & 41.8 & 1010 & 17 & 3.1 & $4.74 \times 10^{-8}$ & $1.46 \times 10^{-8}$ \\
\hline & $\mathrm{V} 1.5-\mathrm{C}$ & 47.1 & 1010 & 22.8 & 3.2 & $4.30 \times 10^{-8}$ & $1.36 \times 10^{.8}$ \\
\hline & $\mathrm{V} 2.0-\mathrm{C}^{\circ}$ & 57.0 & 1010 & 26.3 & 4.8 & $5.14 \times 10^{-8}$ & $2.48 \times 10^{.8}$ \\
\hline & V2.5-( & $\mathrm{NM}$ & 1015 & 32.8 & 8.3 & $4.71 \times 10^{-8}$ & $3.91 \times 10^{-8}$ \\
\hline & V3.0-C & $\mathrm{NM}$ & 1010 & 39.8 & 10.8 & $6.92 \times 10^{-8}$ & $7.48 \times 10^{-8}$ \\
\hline & $P C 0.5-C$ & 47.3 & 1025 & 20.6 & 3.2 & $3.80 \times 10^{-8}$ & $1.22 \times 10^{-8}$ \\
\hline & $P(1.0-C$ & 49.7 & 1020 & 20.1 & 3.5 & $4.38 \times 10^{-8}$ & $1.53 \times 10^{-8}$ \\
\hline & PCI.5-C & 52.7 & 1010 & 21.6 & 3.6 & $3.72 \times 10^{-8}$ & $1.36 \times 10^{-8}$ \\
\hline & PC2.0-C & 58.0 & 1010 & 26.2 & 4.2 & $5.02 \times 10^{-8}$ & $2.09 \times 10^{-8}$ \\
\hline & $P C 2.5-C^{\circ}$ & $\mathrm{NM}$ & 1015 & 32.1 & 9.1 & $6.53 \times 10^{-8}$ & $5.92 \times 10^{-8}$ \\
\hline & $\mathrm{PC} 3.0-\mathrm{C}$ & $\mathrm{NM}$ & 1015 & 36 & 11.0 & $8.00 \times 10^{-8}$ & $8.83 \times 10^{-8}$ \\
\hline & $P(0.5-(1+)$ & 46.5 & 1025 & 19 & 4.0 & $3.75 \times 10^{-8}$ & $1.49 \times 10^{-8}$ \\
\hline & $P C 1.0-(1+)$ & 49.0 & 1015 & 20.7 & 3.0 & $4.08 \times 10^{-8}$ & $1.23 \times 10^{-8}$ \\
\hline & $P C 1.5-C(+)$ & 49.4 & 1010 & 19.6 & 3.7 & $3.41 \times 10^{-8}$ & $1.26 \times 10^{-8}$ \\
\hline & $P(20)(1+)$ & 56.8 & 1010 & 25 & 5.5 & $4.25 \times 10^{-8}$ & $2.33 \times 10^{-8}$ \\
\hline & $P C 2.5-C(+)$ & 79.1 & 1010 & 27.8 & 5.1 & $3.42 \times 10^{-8}$ & $1.74 \times 10^{-8}$ \\
\hline & PC3.0-C(+) & $\mathrm{NM}$ & 1005 & 32.9 & 11.4 & $4.90 \times 10^{-8}$ & $5.58 \times 10^{-8}$ \\
\hline \multirow{18}{*}{ Pizza box } & $\mathrm{V} 0.5-\mathrm{P}$ & 44.44 & 1025 & 18.8 & 3.2 & $4.27 \times 10^{-8}$ & $1.35 \times 10^{-8}$ \\
\hline & $\mathrm{V} 10-\mathrm{P}$ & 47.7 & 1020 & 20.1 & 4.0 & $4.07 \times 10^{-8}$ & $1.62 \times 10^{-8}$ \\
\hline & V1.5-P & 49.0 & 1015 & 22.6 & 4.1 & $4.38 \times 10^{8}$ & $1.80 \times 10^{-8}$ \\
\hline & $\mathrm{V} 2.0 \mathrm{P}$ & 56.4 & 1010 & 24.6 & 5.7 & $4.80 \times 10^{-8}$ & $2.73 \times 10^{-8}$ \\
\hline & $\mathrm{V} 2.5-\mathrm{P}$ & $\mathrm{NM}$ & 1010 & 31 & 8.0 & $6.19 \times 10^{-8}$ & $4.89 \times 10^{-8}$ \\
\hline & Vio-P & $\overline{N M}$ & 1010 & 33.6 & 10.5 & $7.48 \times 10^{8}$ & $7.83 \times 10^{-8}$ \\
\hline & $P(0.5-P$ & 46.4 & 1025 & 20.1 & 3.1 & $4.13 \times 10^{-8}$ & $1.27 \times 10^{-8}$ \\
\hline & $P(1.0-P$ & 47.1 & 1020 & 21.1 & 3.4 & $4.02 \times 10^{-8}$ & $1.35 \times 10^{-8}$ \\
\hline & $P(1.5-P)$ & 52.0 & 1010 & 23.2 & 4.4 & $4.61 \times 10^{-2}$ & $2.03 \times 10^{-13}$ \\
\hline & $P C 2.0-P$ & 55.2 & 1010 & 24.6 & 6.2 & $3.22 \times 10^{-8}$ & $1.98 \times 10^{-8}$ \\
\hline & $P(2.5-P$ & 70.2 & 1015 & 28.7 & 8.2 & $4.37 \times 10^{-8}$ & $3.58 \times 10^{-8}$ \\
\hline & $P(3.0-P$ & $\mathrm{NM}$ & 1015 & 34.3 & 6.2 & $4.83 \times 10^{-8}$ & $3.00 \times 10^{-8}$ \\
\hline & $P(0.5-P(t)$ & 39.4 & 1025 & 16.8 & 2.2 & $3.44 \times 10^{-8}$ & $7.60 \times 10^{-9}$ \\
\hline & $P(10-P(t)$ & 38.5 & 1020 & 17.5 & 1.5 & $3.55 \times 10^{-8}$ & $5.23 \times 10^{-9}$ \\
\hline & $P(1.5-P(+)$ & 40.6 & 1010 & 18.8 & 2.7 & $3.65 \times 10^{-8}$ & $9.91 \times 10^{-9}$ \\
\hline & PC2.0-P(t) & 48.1 & 1000 & 24 & 4.0 & $4.82 \times 10^{-8}$ & $1.93 \times 10^{-8}$ \\
\hline & $P(2.5-P(+)$ & 65.1 & 1015 & 30.2 & 8.0 & $6.96 \times 10^{-8}$ & $5.54 \times 10^{-8}$ \\
\hline & $P(3.0-P(+)$ & $\mathrm{NM}$ & 1015 & 31 & 10.7 & $766 \times 10^{-8}$ & $8.17 \times 10^{-8}$ \\
\hline
\end{tabular}

MFV - Marsh funnel viscosity, MB Mud balance density, FL - Filtrate loss, CT - Thickness of filter cake (t), k/t - Quotient of permeability of tilter cake and thickness of filter cake, $k$ permeability of filter cake, "-C" - C.flute corrugated box, "-P" - P1zza box, " $(+)$ " - sample subjected to additional blending time. NM Not measurable due to flocculatson and bridging in the Marsh funnel device. 

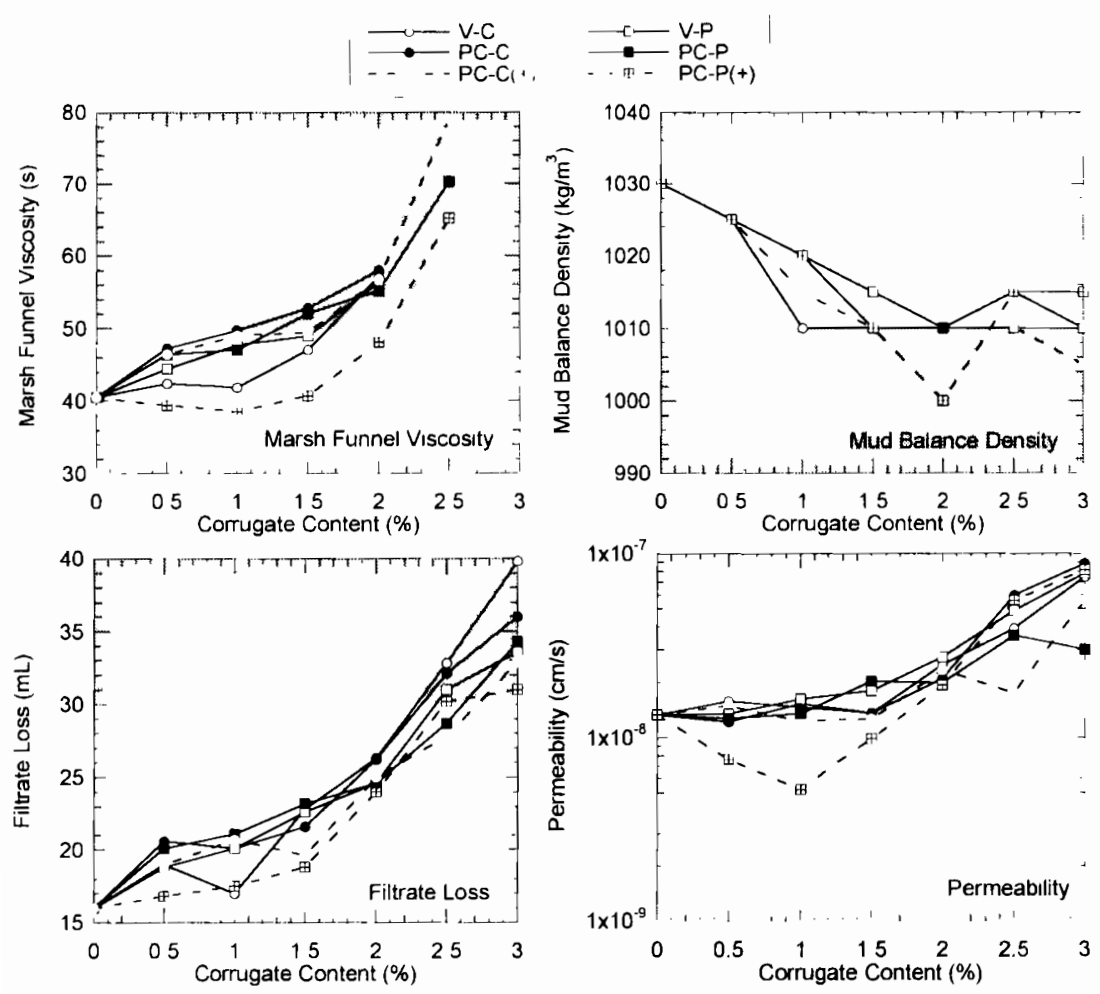

Fig. 2. Engineering Properties of Slurries

The additional blending ume for the post-consumer samples had a more pronounced effect on engineering properties of the slurries containing pizza box fibers than the cflute box fibers. The greater differences were attributed to the breakdown of greasy film on the pizza box allowing access to water and softening during the extended blending. In comparison, the c-flute tibers had already sufficiently broken down after 2 min. of blending and additional blending did not change the behavior significantly.

\section{CONCLUSIONS}

Tests were conducted to assess the feasibility of using corrugated board in slurry applications. Bentonite used in typical slurry mixtures was replaced by fiberized corrugated board at varying ratios. Properties of bentonite-corrugated board-water mixes were compared to baseline bentonite-water slurry mixes to evaluate the influence and practical limits of corrugated board addition to the mixes. The results indicated that the corrugated board could be used to replace 9 to $27 \%$ (corresponding to 0.5 to $1.5 \%$ corrugate content in a $5.5 \%$ mixture) of the bentonite used in the slurry 
mixes based on Marsh funnel viscosity, density, and filtrate loss tests. Corrugated board may be used to replace up to $36 \%$ of bentonite $(2.0 \%$ corrugate in a $5.5 \%$ mixture) for specitic site and construction conditions requiring high MFV. In addition, permeability of the mixes with corrugated board was similar to baseline bentonite-water mix permeability. The differences in engineering properties of the slurries containing corrugate content were attributed to the presence of a fibrous matrix that inlluenced viscosity and how characteristics. Overall, slurry applications provide a new and viable beneficial reuse alternative for paper / paperboard products, which constitute the largest weight and volume fraction of municipal solid waste generated and disposed of in the U.S. as well as other countries.

\section{ACKNOWLEDGMENTS}

This study was partially supported by Office of Naval Research (Award No. N0001408-1-0855). Mr. Timothy Kershaw and Mr. Matthew Anderson assisted with laboratory testing.

\section{REFERENCES}

Boyes, R. G. H. (1975). Structural and Cut-off Diaphragm Walls, Applied Science Publishers Ltd., London, England.

D'Appolonia, D. J., "Soil-Bentonite Slurry Trench Cutoffs," Journal of the Geotechnical Engineering Division, ASCE. 106, GT4, 399-417.

Flaherty, R. (2009). Personal communication, President, International Corrugated Packaging Foundation. December 19, 2009.

ISTA (2009). International Safe Transit Association, "ISTA 2 Series Partial Simulation Performance Test Procedure," hitp://ww.ista.org/forms/ IAoverview.pdf, last accessed December 26, 2009.

Paper Industry Association Council (2008). "2007 Recovered Paper Annual Statistics," hitp//stats.paperrecycles.org/. Paper Industry Association Council, last accessed May 6, 2008.

RecycleBank (2009). "The Pizza Box Recycling Mystery," http://www.recyclebank. com/recycling/recl'ling-101/330-the-pizza-box-recycling-mystery, last accessed December 17, 2009.

Ryan and Day (2003). "Soil-Bentonite Slurry Wall Specifications," Proceedings, Soil and Rock America 2003, 12th Panamerican Conference on Soil Mechanics and Geotechnical Engineering, P. J. Culligan, H. H. Einstein, and A. J. Whittle, Eds.

White, A. and Kendrick, J. (2009). Recycling Paper Food Packaging with Corrugated Cardboard: A Proposal for a New Recyclability and Repulpability Protocol and Preliminary Test Results for Fiber-Based Hot Cups, Global Green USA's Coalition for Resource Recovery, New York.

USEPA (2009). "Municipal Solid Waste in the United States - 2007 Facts and Figures." http://wwwepa.gov/epawaste/nonhaz/municipal/pubs/msw07-rpt.pdf, last accessed August 26, 2009.

USEPA (1984). Slurry Trench C'onstruction for Pollution Migration Control, EPA540/2-84-(0)1. Washington D.(' 